\title{
Gold(I)-Catalyzed Stereoselective Synthesis of Deoxyglycosides
}

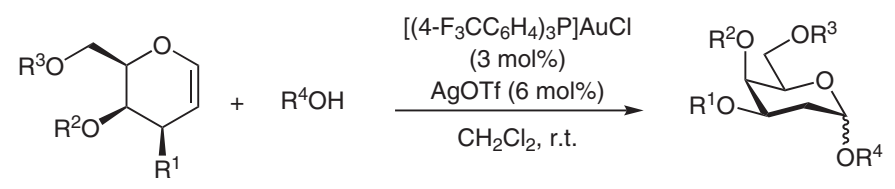

Metal-Catalyzed

Asymmetric

Synthesis and

Stereoselective

Reactions

\section{Key words}

gold catalysis

deoxyglycosides

glycals

alkoxylation

Selected examples:
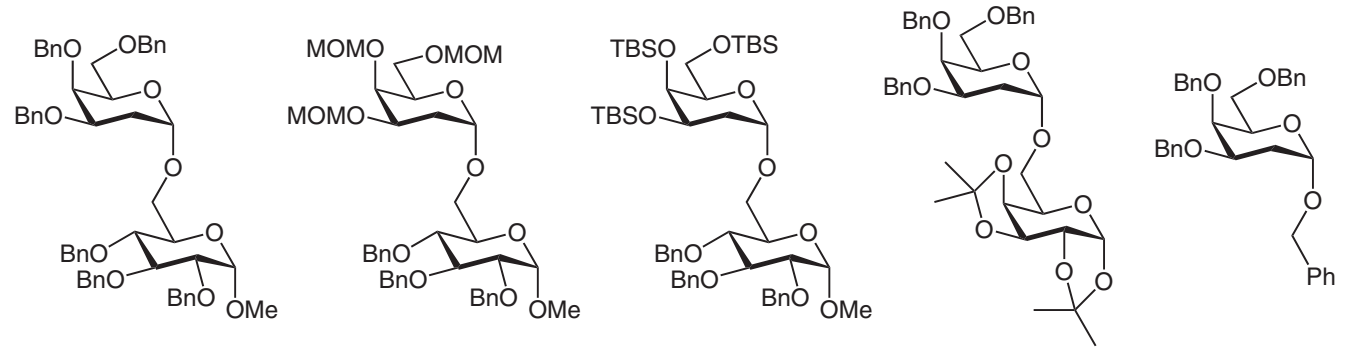

$89 \%$ yield

$76 \%$ yield

$78 \%$ yield

$79 \%$ yield

$85 \%$ yield

Proposed mechanism:

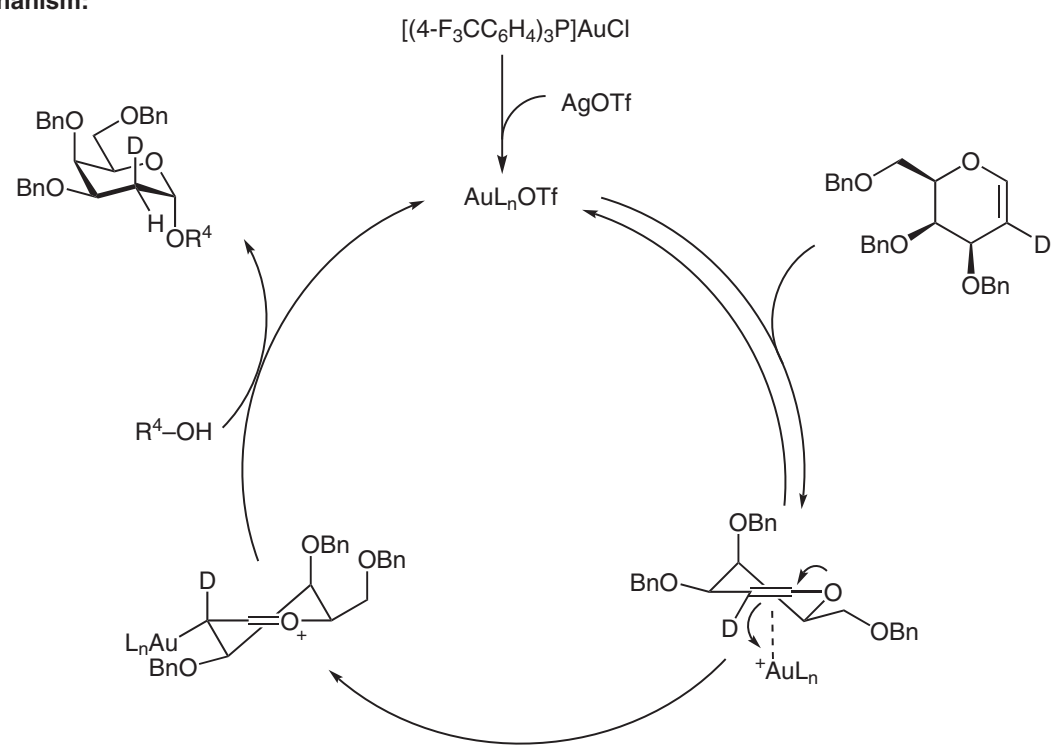

Significance: Deoxyhexose structures can be found in a wide range of natural products. The authors have developed an $\alpha$-stereoselective catalytic synthesis of deoxyglycosides from glycals by using $\mathrm{Au}(\mathrm{I}) / \mathrm{AgOTf}$.
Comment: The reaction can be applied to a broad range of glycals and alcohols to give $\alpha$-deoxyglycosides in high yields and with excellent selectivity. The utility of the reaction was demonstrated by the synthesis of oligosaccharides through the coupling reaction followed by deprotection.

SYNFACTS Contributors: Hisashi Yamamoto, Takahiro Sawano

Dol: 10.1055/s-0036-1591077; Reg-No.: H16117SF 